\title{
PAISAGISMO E PAISAGEM INTRODUZINDO QUESTÕES
}

\section{SILVIO SOARES MACEDO}

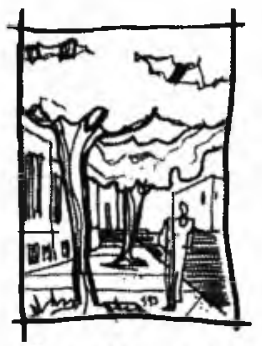

As questões sobre paisagismo e paisagem são emergentes. Na atualidade as drásticas transformações impressas nos três últimos séculos sobre o planeta criaram e recriaram lugares, eliminaram importantes e curiosas formas de vida e extinguiram recursos naturais significativos.

Em um contexto de expansão populacional, em especial a urbana, típica deste período, os conflitos sociais são inúmeros. Existe uma crise real de qualidade de vida que perpassa por praticamente todos os aglomerados urbanos e cada vez são maiores as necessidades de espaços para a produção agrícola, a geração de energia, a captação de águas, etc., enfim para a produção de insumos à sociedade humana.

Neste universo de transformações o Paisagismo surge como uma forma de conhecimento e um instrumento indicador de ações que procuram dar algumas respostas que objetivam contornar uma série de problemas detectados nas diferentes formas de organização espacial produzidas. Seriam estes por destruição e eliminação de vegetação nativa ou replantada, a eliminação de elementos construídos "caros" à comunidade, como velhos e queridos edifícios, a degradação dos solos e outros mais.

$\mathrm{Na}$ forma que hoje conhecemos o paisagismo surge, ainda a nível embrionário, na Inglaterra, do início do séc. XIX e se consolida nos Estados Unidos da segunda metade deste século, em especial, devido ao trabalho dos integrantes do denominado "Park Movement" encabeçados por Olmestead. A partir do final do séc. XIX. surgem ainda as primeiras escolas de paisagistas e a profissão se consolida pelo país.

No Brasil, o trabalho de arquitetos paisagistas, ainda que isolados surge a partir do meio do mesmo século e profissionais como Glaziou, no Rio de Janeiro, trabalham para a corte em trabalhos como o Paço Imperial e o Campo de Santana. 


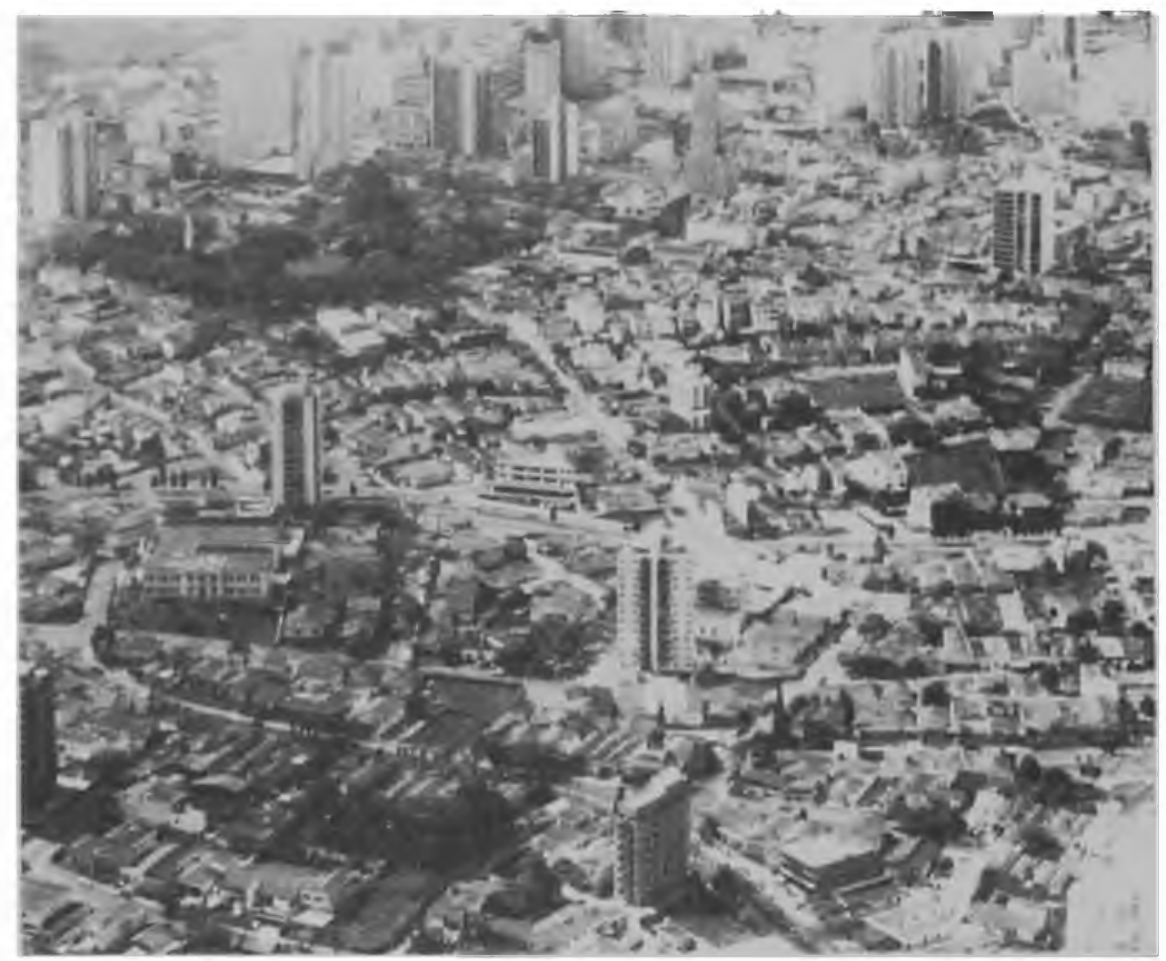

Foto 1 - Vista aérea de

São Paulo - no caso

- Vale do rio Tietê

no seu trecho

netropolitano, área

intensamente

processada de

modo a se adequar

ao uso humano

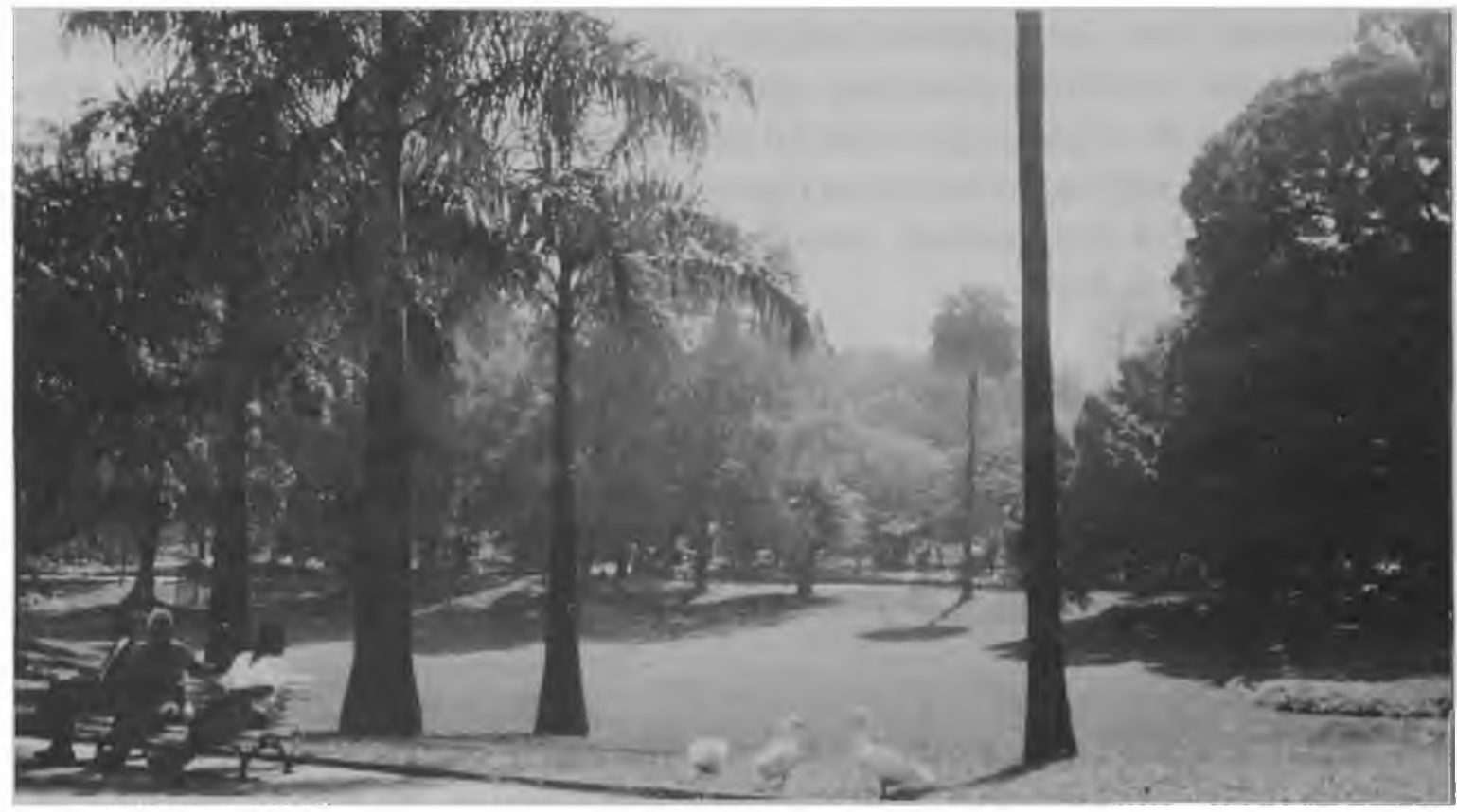

Foto 2 O Campo de Santana, atual praça da República na cidade do Rio de Janeiro ainda mantém intaclo seu antigo desenho, com canteiros sinuosos, arvoredos, lagos e gramados típicos do ecletismo no paisagismo brasileiro 
No séc. XX vários profissionais surgem no mercado de trabalho produzindo diversas e importantes obras. em especial de caráter urbano. como Bouvard (São Paulo - 1913), Dieberguer (São Paulo - 1910-1940). Zimber (São Paulo - 19101930) e outros mais, sempre atendendo às solicitações do poder público - praças, parques e boulerards ou de particulares (jardins e parque de residências).

Nos anos 30 e 40, Roberto Burle Marx introduz seus primeiros trabalhos, revolucionando o modo de projetar os espaços livres principalmente as praças e jardins, conferindo a eles formas e volumes derivados de sua experiência como artista plástico. Pode-se considerar que surge pela primeira vez no país uma forma tipicamente brasileira de projetar em paisagismo, que apesar de muito pessoal do autor, que revoluciona os modos de concepção plástica dos espaços livres e cria-se uma escola projetual, que se fundamenta entre outros princípios no uso extensivo da vegetação brasileira (antes preterida nos projetos dos bons arquitetos paisagistas), na utilização de formas orgânicas em pisos de mosaico português e no trabalho com a água.

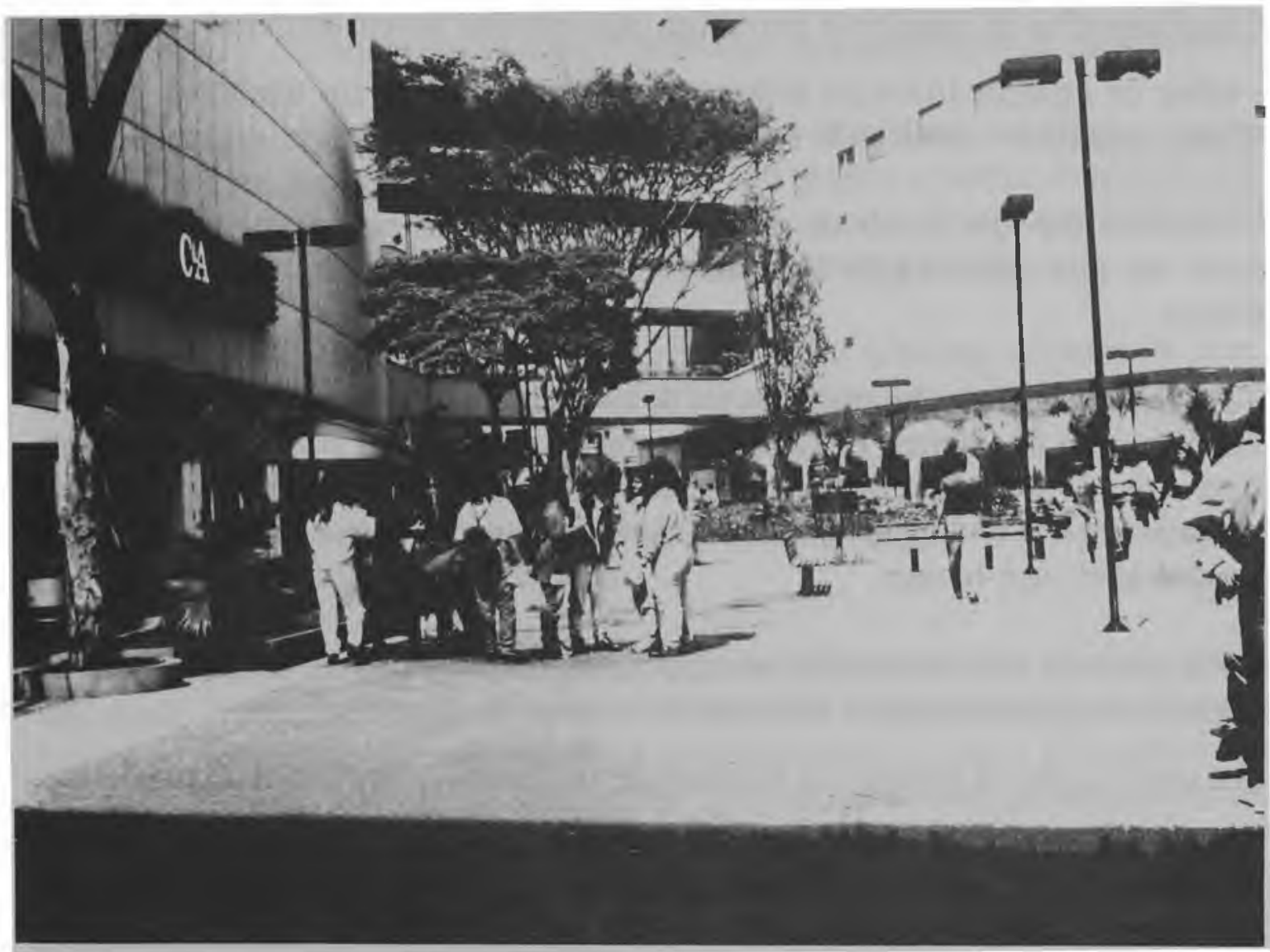

Foto 3 - Os projetos concebidos por Burle Marx e sua equipe conferem uma marca especial a cada espaço. No caso, os pisos em mosaico, de curvas sinuosas da praça do Shopping West Plaza em São Paulo 
Os princípios adotados por Burle Marx orientam a partir dos anos 50 e 60 toda uma nova geração de arquitetos paisagistas que se forma em especial nos estados do Sul do país (São Paulo, Rio de Janeiro e Rio Grande do Sul) ${ }^{1}$

\section{PAISAGISMO}

Pode ser entendido como "um processo consciente de manejo, planejamento e mudança física da paisagem envolvendo o seu manejo e o projeto de lugares (aqui considerados como segmentos específicos de uma paisagem total) 2"

Esta definição de John Motloch praticamente explicita a postura mais atual da A.S.L.A American Society of Landscape Architects. Esta, em 1983, apresenta o trabalho do paisagista como "A profissão que utiliza princípios artísticos e científicos na construção de ambientes ${ }^{3 "}$ Esta postura sucede-se a outras anteriores, que atribuíam ao paisagismo exclusivamente o caráter de arte, conferindo depois de décadas um caráter técnico à profissão, portanto menos subjetivo perante a sociedade.

Como universo de trabalho o paisagista atua em dois níveis distintos:

sobre os espaços livres de urbanizaçāo - na escala de um território, de uma região, sugerindo e indicando formas de avaliação e atuação.

sobre os espaços livres de edificaçâo na escala da cidade, utilizando-os como um instrumento para a discussão da configuração e da qualidade de vida urbana.

Tanto em uma, como em outra escala de abordagem, o trabalho com a paisagem visa a criação de lugares, espaços humanos para um futuro próximo ou distante. Esta visão de trabalho com a paisagem está ligada a uma conceituação do que ou quais seriam os lugares ideais de vida, de moradia da sociedade em um determinado espaço-tempo.

Cada proposta de intervenção ou atuação, cada projeto deve então, dentro da ótica do paisagista respeitar três princípios básicos que seriam:

a) a observação e a procura da manutenção da dinâmica ecológica do lugar;

b) o atendimento prioritário às necessidades da população, tanto em termos qualitativos (em termos de conforto ambiental, acessibilidade à água limpa, etc.) como quanto funcionais;

c) obedecer, criar e recriar padrões estéticos adequados à população local (futura ou presente) e ao lugar ${ }^{4}$. 


\section{NÍVEIS DE ATUAÇÃO}

A aplicação dos pressupostos especificados no item anterior se dá da seguinte forma nos dois níveis apontados:

1. Nos processos de ocupação e alienação do território, estabelecendo-se critérios de onde e como urbanizar ou ocupar e linhas de implementação destas formas de assentamento.

Basicamente são trabalhos executados em equipe e que visam ao estabelecimento de planos de manejo, áreas de proteção ambiental, planos e seus zoneamentos de caráter paisagístico/ambiental, parques, áreas de conservação e preservação, políticas de atuação, etc.

Quanto maior for a escala de atuação, o porte do teirritório a ser atingido, mais genéricas serão as posturas a serem adotadas, que passam a ter um caráter indicativo para políticas gerais e para planos e intervenções setoriais e pontuais, que terão sempre como objetivo central a construção ou manutenção de paisagens.

2. Dentro das estruturas urbanas todo o trabalho se alicerça na figura dos denominados espaços livres de edificação, que são objetos centrais de trabalho do paisagista ${ }^{5}$. Estes espaços são todos aqueles não contidos dentro das edificações e englobam ruas, pátios, largos, praças, parques, terrenos baldios, etc.

As atividades do paisagista são apoio direto a planos urbanos, projetos de desenho urbano e praticamente definem critérios e posturas de projeto para tais espaços.

Todo o enfoque se centra sobre a constituição morfológica destes lugares e seus critérios de organização e distribuição.

No Brasil a ação do paisagismo está em geral restrita ao projeto das denominadas áreas "verdes" como jardins, praças, parques, calçadões e na colaboração esporádica em planos diretores ou de manejo ambiental, sendo a formação básica do profissional, advinda de áreas diversas como agronomia, arquitetura e engenharia florestal.

Por este fato seu entendimento social está extremamente vinculado à idéia do jardim, do trabalho com a vegetação ${ }^{6}$. 


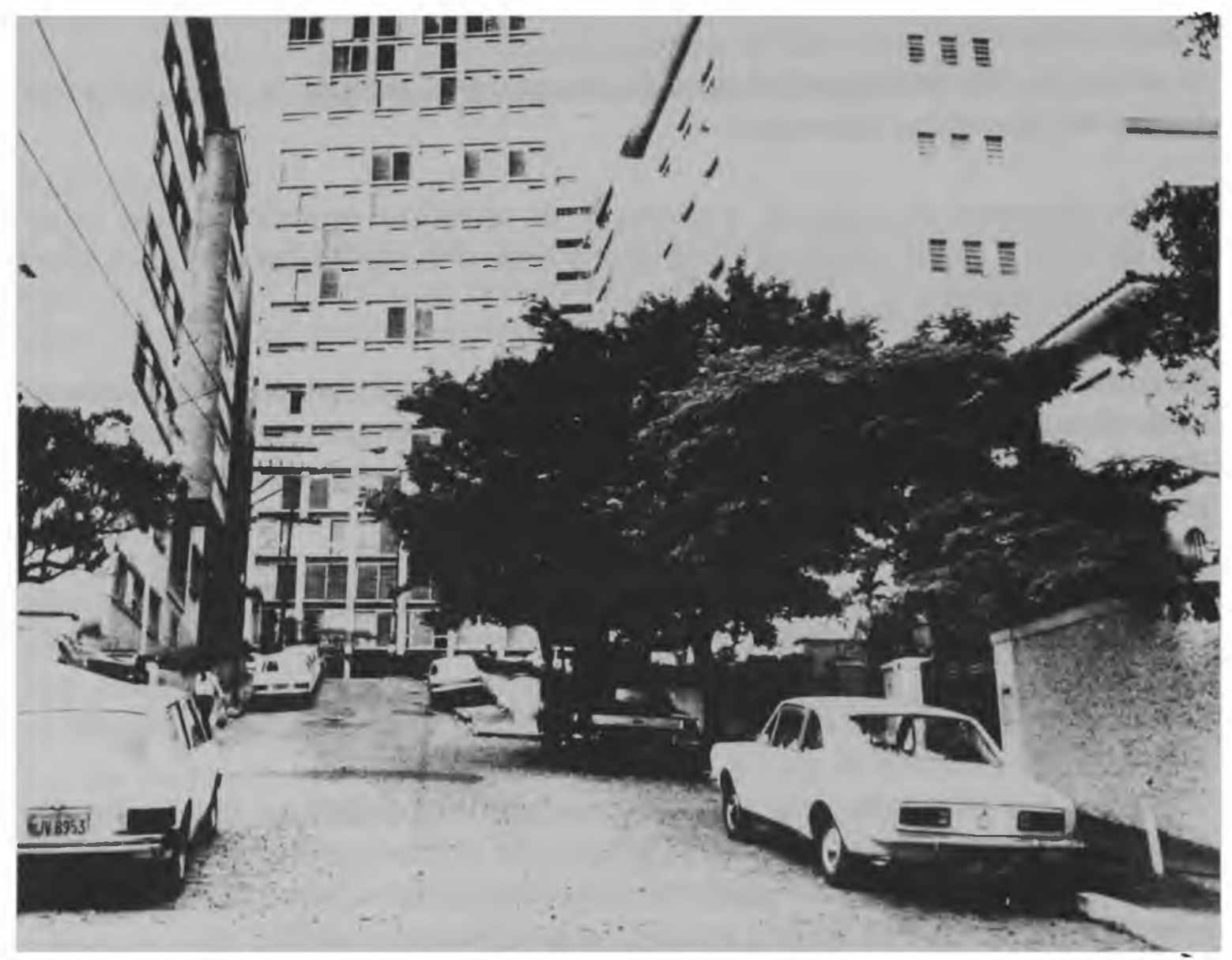

Foto 4 - O espaço fora das edificações - denominado de espaço livre, vazio ou de qualquer outra foma no caso una rua do bairro de Higienópolis en São Paulo

\section{PAISAGEM}

Constitui-se no universo de trabalho do paisagista e de fato uma estrutura na qual este só em situações especiais atua. Possui diversas acepções entre as quais adotamos a seguinte:

Paisagem a expressão morfológica em um determinado tempo, do processo constante de ação dos seres vivos sobre os diversos pontos do planeta associados ao movimento contínuo das diferentes estruturas geológicas e águas.

A paisagem não é estática e pode ser considerada como um sistema complexo de relações que para ser compreendida necessita de muito mais informações que o mero olhar nos pode oferecer ${ }^{7}$ 


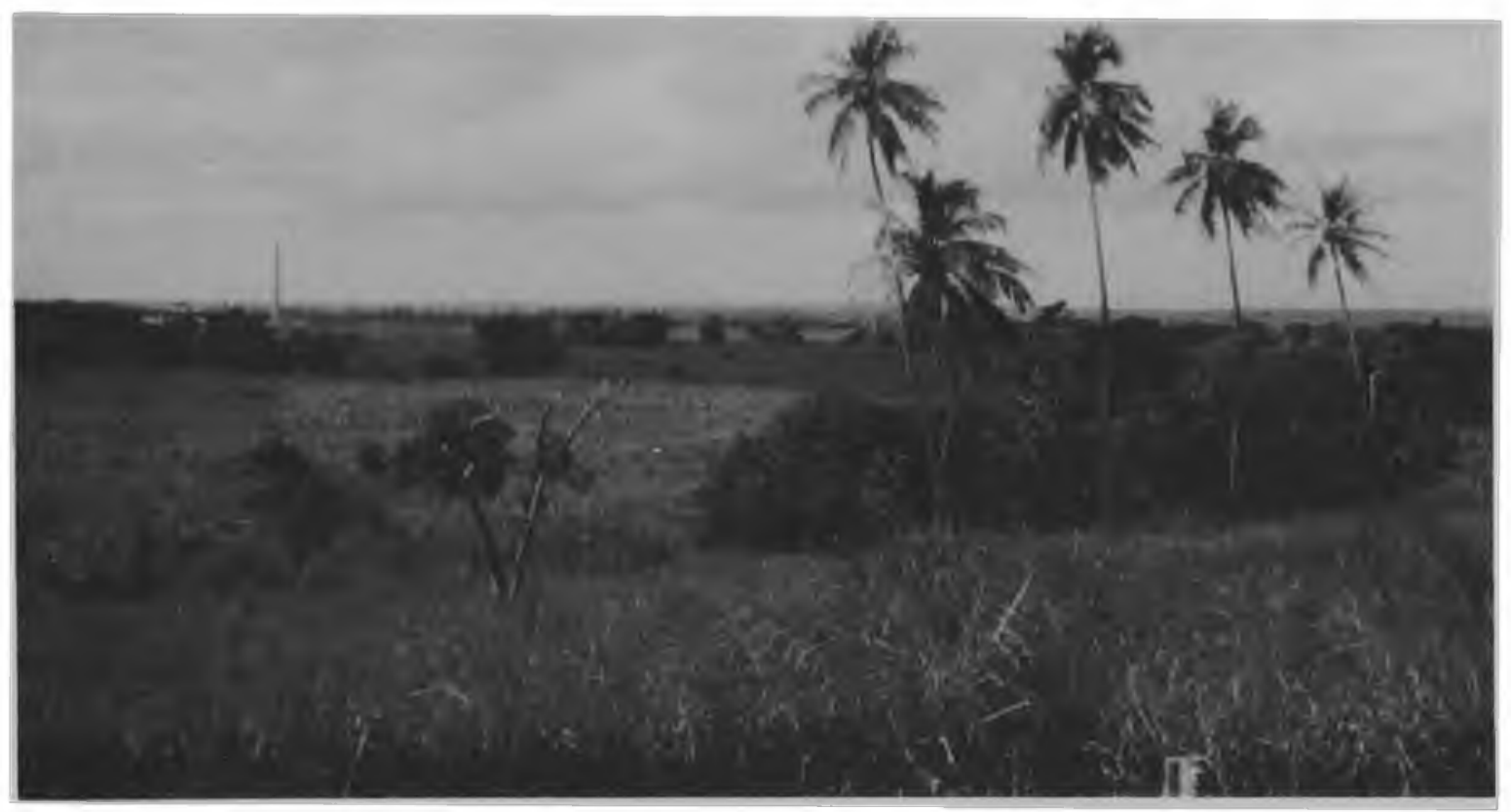

Foto 5 Vista de canmpos cultivados no Rio Grande do Norte, una paisagem bucólica, mas altamente processada há décadas e por gerações para a produção agrícola

Outras interpretações sobre a paisagem confirmam de um modo direto tais posições:

"A paisagem é o reflexo da dinâmica dos sistemas sociais e naturais ... e varia de acordo com as características fisiográficas e ambientais e com as intervenções humanas sobre ela implementadas"8. sendo estas posições reforçadas por Motloch que afirma que "no entendimento contemporâneo paisagem é um termo abrangente, que inclui o que se denomina espaços naturais e urbanos"9

Para uma compreensāo e avaliação mais apurada da paisagem, dentro de uma visão sistêmica se costuma dividi-la em algumas categorias de elementos, que associados entre si, dentro do citado processo dinâmico de mutação. permitem ao estudioso a criação de métodos e técnicas de avaliação.

Seriam:

Suporte físico: solo, subsolo e águas com sua dinâmica:

Cobertura vegetal;

Estruturas urbanas/massas de edificação; 
Comunidades de seres vivos: podendo-se no caso criar um subitem especial para a comunidade humana, seus veículos e instituições ${ }^{10}$

Cada um destes elementos só pode então ser dissociado em processos iniciais de entendimento, sendo então posteriormente reassociados entre si.

Esła divisão direciona as formas de atuação do paisagista, que ao elaborar sobre qualquer lugar, tem obrigatoriamente que considerar tais elementos nas suas diferentes formas e níveis de interação, de modo a alcançar os princípios explicitados anteriormente (vide item Paisagismo p. 3)

Não se privilegia no estabelecimento de planos e projetos somente este ou aquele elemento, como água ou solos adequados no estabelecimento de planos e projetos paisagísticos, mas sim a dinâmica de cada lugar e suas possibilidades de interação com novas estruturas espaciais ${ }^{11}$.

Como resultado, as técnicas paisagísticas de análise e avaliação de lugares e suas paisagens, refletem em suas estruturas este tipo de enfoque, como se pode observar por exemplo nos trabalhos mais recentes de John Lyle e seus seguidores.

\section{NOTAS}

(1) Vide MACEDO, Silvio S. A Vegetação como elemento de projeto. In: Paisagem e Ambiente - Ensaios $N$, São Paulo: FAUUSP, 1992, p. 11-41.

(2) Vide MOTLOCH. Introduction to landscape design. p. 2.

(3) Para maiores detalhes e discussão das posturas diferentes da ASLA consultar: LEITE. Maria Angela Faggin Pereira. Novos valores: destruiçāo ou desconstruçāo? p. 36-40.

(4) "A forma pela qual a paisagem é projetada e construída reflete uma elaboração filosófica e cultural, que resulta tanto da observação objetiva do ambiente, quanto da experiência individual ou coletiva em relação a ela". Em LEITE, Maria Angela F. P. Novos valores; destruiçāo ou desconstruçāo? p. 23.

(5) Vide para maiores esclarecimentos os textos produzidos pela Profa. Dra. Miranda M. Magnoli, que desenvolveu toda uma conceituação sobre o assunto, em especial na sua tese de livre-docência, na qual dedica um capítulo especial para o assunto.

(6) As próprias posturas divulgadas por Burle Marx, nosso mais importante paisagista nos reportam frequientemente a figura do jardim, como o foco e a panacéia dos problemas dos assentamentos humanos.

"A larga e muito ampla experiência do meu trabalho de paisagista, criando, realizando e conservando jardins, parques e grandes áreas urbanas, pernite-me agora formular a conceituação que faço do problema jardim, como sinônimo de adequaçāo (grifo nosso) do meio ecológico para atender as exigências naturais da civilização. In: Marx, Roberto B. Arte e Paisagem, p. 11. 
(7) "Paisagem não é estática, pois todos os seus elementos constituintes são possíveis de transformações próprias, como também se alteram mutuamente e um território é formado por um número infinito de paisagens, parcialmente justapostas" In: Marx, Roberto B. Arte e Paisagem, p. 55 e 57.

(8) LAURIE, Michael. An introduction to landscape architecture. p. 1.

(9) Vide SANTOS, Milton. Espaço e método.

(10) idem.

(11) Vide LYLE, John. Design with human ecosystens.

\section{BIBLIOGRAFIA}

MARX, Roberto B. Arte e Paisagem - conferências escolhidas. São Paulo: Nobel, 1987.

PELLEGRINO, Paulo R. A paisagem possível. In: Paisagem e Ambiente - Ensaios III, 2a ed. São Paulo: FAUUSP, 1991.

LEITE, Maria Angela F P. Novos valores: destruiçāo oul desconstruçāo? São Paulo, 1992. Tese (Doutorado) - FAUUSP

LAURIE, M. An introduction to landscape design. New York: Van Nostrand Reinhold. 1991.

MACEDO, Silvio S. Paisagem, Urbanizaçāo e Litoral do éden à cidade. São Paulo, 1993. Tese (Livre-Docência) - FAUUSP.

MAGNOLI, Miranda M.E.M. Notas de aula e seminários das disciplinas AUP-810 e AUP-222. São Paulo: FAUUSP.

TOBEY. A history of landscape architecture.

SANTOS, Milton. Espaço e método. São Paulo: Nobel.

Fotos: Fornecidas pelo autor. 